\title{
Protein-Binding Characteristics of Voriconazole Determined by High-Throughput Equilibrium Dialysis
}

\author{
KIM VANSTRAELEN, ${ }^{1}$ JOOST WAUTERS, ${ }^{2}$ HENRIETTE DE LOOR, ${ }^{3}$ INE VERCAMMEN, ${ }^{1}$ PIETER ANNAERT, ${ }^{4}$ \\ KATRIEN LAGROU, ${ }^{5}$ ISABEL SPRIET ${ }^{1}$
}

\begin{abstract}
${ }^{1}$ KU Leuven Department of Pharmaceutical and Pharmacological Sciences, Clinical Pharmacology and Pharmacotherapy, University Hospitals Leuven, Leuven 3000, Belgium

${ }^{2}$ Clinical Department of General Internal Medicine, Medical Intensive Care Unit, University Hospitals Leuven, Leuven 3000, Belgium

${ }^{3} \mathrm{KU}$ Leuven Department of Microbiology and Immunology, Laboratory of Nephrology and Renal Transplantation, University Hospitals Leuven/Catholic University Leuven, Leuven 3000, Belgium

${ }^{4}$ KU Leuven Department of Pharmaceutical and Pharmacological Sciences, Drug Delivery and Disposition, O\&N2, Leuven 3000, Belgium

${ }^{5}$ KU Leuven Department of Microbiology and Immunology, Clinical Department of Laboratory Medicine, University Hospitals Leuven, Leuven 3000, Belgium
\end{abstract}

Received 3 April 2014; revised 2 June 2014; accepted 3 June 2014

Published online 24 June 2014 in Wiley Online Library (wileyonlinelibrary.com). DOI 10.1002/jps.24064

\begin{abstract}
Plasma protein binding (PPB) can possibly alter the already variable pharmacokinetics of voriconazole. Voriconazole PPB was determined only once, being $58 \%$, according to equilibrium dialysis (ED). We investigated voriconazole PPB more in detail, with a convenient and newer high-throughput ED assay (HT-ED), in human blank plasma spiked with voriconazole and in plasma from intensive care unit (ICU) patients treated with voriconazole. HT-ED was conducted in a 96-well plate, setup against phosphate-buffered saline. Voriconazole concentrations were measured by liquid chromatography-tandem mass spectrometry. The median PPB was $47.6 \%$ [interquartile range (IQR) $45.3 \%-50 \%$ ] in vitro, and $49.6 \%$ (IQR $42.5 \%-52.5 \%$ ) in ICU samples $(p=0.35$ ), and is not depending on total voriconazole concentration $(0.7-11.2 \mathrm{mg} / \mathrm{L}, p=0.65)$. The drug mainly binds to albumin $(25.5 \pm 5.1 \%)$, and to a lesser extent to $\alpha$-1-acid glycoprotein (AAG; $4.8 \pm 1.2 \%)$. The HT-ED assay can be performed at $37^{\circ} \mathrm{C}$ or $25^{\circ} \mathrm{C}(p=0.44)$ and in batch: PPB variations during freeze-thaw cycles $(p=0.13)$ and during frozen storage up to 12 months $(p=0.10)$ were not clinically relevant. Voriconazole PPB is approximately 50\%, according to HT-ED. As albumin and AAG only account for approximately $30 \%$ of total voriconazole PPB, other plasma components could influence PPB and therefore efficacy or toxicity because of variations in unbound fractions. $\odot 2014$ Wiley Periodicals, Inc. and the American Pharmacists Association J Pharm Sci 103:2565-2570, 2014
\end{abstract}

Keywords: voriconazole; pharmacokinetics; protein binding; unbound fraction; high-throughput technologies; equilibrium dialysis; albumin; $\alpha$-1-acid-glycoprotein

\section{INTRODUCTION}

Since the launch of voriconazole, the first-line treatment for invasive aspergillosis, ${ }^{1}$ its extreme inter- and intraindividual variability in exposure has been a challenge in setting an adequate therapy regimen. ${ }^{2-11}$ Several factors influencing voriconazole plasma concentrations have been identified over the last few years, such as saturable metabolism by CYP2C19, CYP2C9 and CYP3A4,,${ }^{11-13}$ CYP2C19 polymorphism, ${ }^{14,15}$ drug accumulation in liver disease, ${ }^{16}$ influence of age on its metabolism, ${ }^{9}$ coadministration with CYP2C19- and CYP3A4interacting comedication, ${ }^{9}$ i.v. to oral switch, ${ }^{9,12,17,18}$ and impact of food, ${ }^{19,20}$ all resulting in large intra- and interpatient variability. Plasma protein binding (PPB) of voriconazole has, however, never been investigated as a factor causing variations in voriconazole plasma concentrations. Yet, this would be interesting, as only unbound drug concentrations exert pharmacological activity. For drugs with linear pharmacokinetics, hypoalbuminemia only seems to have relevant clinical impli-

Correspondence to: Kim Vanstraelen (Telephone: +32-16-34-23-39; Fax: +3216-34-30-84; E-mail: Kim_vanstraelen@hotmail.com)

Journal of Pharmaceutical Sciences, Vol. 103, 2565-2570 (2014)

(C) 2014 Wiley Periodicals, Inc. and the American Pharmacists Association cations in case of high protein binding $(>70 \%) .{ }^{21}$ However, in drugs with nonlinear pharmacokinetics, such as voriconazole, an effect can probably be seen also for drugs with lower PPB, because elevated unbound concentrations, resulting from hypoalbuminemia, cannot be eliminated immediately because of saturated hepatic metabolism.

A first step in exploring the influence of hypoalbuminemia on voriconazole protein-binding characteristics is the development of a robust, reliable, and easy-to-use method for determining voriconazole-unbound and voriconazole-bound concentrations. Moreover, in vitro tests are needed to determine voriconazole PPB in a reliable manner, enabling us to reveal alterations in voriconazole PPB because of hypoalbuminemia in a future project.

The most common methods for investigating protein binding of drugs in vitro include equilibrium dialysis (ED), ultracentrifugation, and ultrafiltration..$^{22-25} \mathrm{ED}$ is the method of choice in research settings, using a semipermeable membrane to separate unbound and bound fractions with subsequent analysis of drug concentrations. ${ }^{22-25}$ It is typically considered to be the gold standard, minimizing nonspecific binding of compounds to the device and avoiding the need for large plasma volumes. ${ }^{24,26}$ Voriconazole PPB was previously reported to be $58 \%$, according 
to ED results in premarketing studies, using a Dianorm Dialyzer (Harvard Bioscience Inc., Holliston, Massachusetts). ${ }^{27}$ No data are available about the impact of technical factors potentially influencing PPB of voriconazole, such as temperature during ED, mass balance, volume shift, freeze-thaw cycles, and frozen storage. Nowadays, newer high-throughput ED (HT-ED) assays are available ${ }^{28,29}$ (such as HTDialysis, Gales Ferry, Connecticut; ThermoFisher Scientific, Waltham, Massachusetts; Spectrum Laboratories, Laguna Hills, California) that are more user-friendly and more accurate compared with former ED devices, because of even less nonspecific binding to perform ED. ${ }^{24,29}$ HT-ED also allows minimal volume sampling in a clinical patient setting. ${ }^{24,29}$

In this study, a robust and easy-to-use HT-ED assay is tested for the determination of voriconazole PPB. Moreover, the influence of several technical factors during HT-ED on PPB characteristics of voriconazole was investigated more in detail, both in vitro as in vivo.

\section{MATERIALS AND METHODS}

\section{Chemicals and Solutions}

Voriconazole ( $0.35 \mathrm{kDa})$ was provided by Pfizer (New York) and was used to prepare a stock solution of $3493 \mathrm{mg} / \mathrm{L}$ in methanol (LC-MS grade from Acros Organics, Geel, Belgium). This stock solution was further diluted in phosphate-buffered saline (PBS, $0.01 \mathrm{M}$ phosphate buffer, 0.0027 $\mathrm{M} \mathrm{KCl}$, and 0.137 $\mathrm{M} \mathrm{NaCl}, \mathrm{pH}$ 7.4) to the appropriate concentrations for the different experiments. $\alpha$-1-acid glycoprotein (AAG) from Sigma-Aldrich BVBA (Diegem, Belgium) was used to prepare PBS solutions of $1 \mathrm{~g} / \mathrm{L}$. Albumin solutions were prepared in PBS, at a concentration of $40 \mathrm{~g} / \mathrm{L}$, with Albunorm ${ }^{\circledR}$ (Octapharma, Benelux, Belgium), Albumin ${ }^{\circledR} 20 \%$ (CAF, Brussels, Belgium), and Flexbumin ${ }^{\circledR}$ $200 \mathrm{~g} / \mathrm{L}$ (Baxter, Braine-l'Alleud, Belgium). All solutions were freshly prepared at the moment of the experiments.

HPLC-graded water was generated using a Milli-Qwater-purification system (Merck Millipore, Billerica, Massachusetts). Ethanol was bought from Prolabo VWR (Amsterdam, The Netherlands). Pooled blank lithium heparin plasma was collected from healthy volunteers. Samples from intensive care unit (ICU) patients, treated with voriconazole for at least 4 days, were collected into lithium heparin tubes without gel separator, after approval by the local Ethical Committee and signing of the informed consent form. After centrifugation (10 min, $1500 \mathrm{~g})$, plasma was stored at $-20^{\circ} \mathrm{C}$ until further analysis.

\section{HT-ED Followed by Liquid Chromatography-Tandem Mass Spectrometry}

\section{Procedure}

High-throughput ED was performed using a Teflon 96-well ED device and dialysis membranes (molecular weight cut-off 12-14 kDa) from HTDialysis (model HTD96b). Prior to use, the dialysis membranes were soaked for $60 \mathrm{~min}$ in $100 \% \mathrm{PBS}$, followed by $20 \mathrm{~min}$ in PBS with $20 \%$ ethanol. Before placing the membranes in the ED device, membranes were rinsed thoroughly with Milli-Q water so that they could be separated. In each well, $150 \mu \mathrm{L}$ PBS buffer was loaded in the dialysate side against $150 \mu \mathrm{L}$ investigational solution at the other side of the semipermeable membrane, through which only unbound molecules diffuse until equilibrium. Equilibration was carried out during shaker incubation (150 rpm) (model Edmund Bühler GmbH; type KS-15 control; Glasatelier Saillart, Meerhout, Belgium) at $37^{\circ} \mathrm{C}$ (Edmund Bühler $\mathrm{GmbH}$; TH15; Glasatelier Saillart), whereas the device was covered with an adhesive sealing film (HTDialysis), preventing evaporation of carbon dioxide $\left(\mathrm{CO}_{2}\right)$ and $\mathrm{pH}$ changes. After reaching the equilibrium, solutions from both compartments were stored at $-20^{\circ} \mathrm{C}$ until analysis.

Determination of unbound and bound voriconazole concentrations was carried out using a previously in-house developed and validated liquid chromatography-tandem mass spectrometry (LC-MS/MS) method, with a LLOQ of $0.2 \mathrm{mg} / \mathrm{L}$, betweenrun precision, expressed as coefficient of variation, below $12 \%$ and accuracy, expressed as a percentage of the theoretically added concentration, between $89 \%$ and $109 \%$. Linearity was demonstrated from 0.06 to $20.0 \mathrm{mg} / \mathrm{L} .^{30}$

\section{Calculation of PPB of Voriconazole}

The percentage of unbound voriconazole was calculated using the following formula ${ }^{22}$ :

$$
\mathrm{UF} \%=\frac{[\text { voriconazole }]_{\mathrm{PBS}}}{[\text { voriconazole }]_{\text {plasma }}} \times 100
$$

in which UF\% stands for the percentage of unbound voriconazole. [Voriconazole] $]_{\mathrm{PBS}}$ and [voriconazole] $]_{\text {plasma }}$ represent the concentration of voriconazole at equilibrium, in the buffer compartment and plasma compartment, respectively.

\section{Factors Influencing PPB During HT-ED}

Time to equilibrium was determined using human blank plasma, spiked with voriconazole at three clinically relevant concentrations $(1.75,3.5$, and $14 \mathrm{mg} / \mathrm{L})$. Voriconazole concentrations and unbound fractions were determined after 1, 2, 4, and $6 \mathrm{~h}$ of equilibration.

Mass balance was checked to rule out nonspecific adsorption of voriconazole to the device, by comparing a total voriconazole concentration of $3.4 \mathrm{mg} / \mathrm{L}$ in the plasma samples before HT$\mathrm{ED}$ and the sum of the recovered voriconazole amounts in the buffer and plasma compartment after HT-ED.

All the latter in vitro tests were conducted using human blank plasma spiked with different concentrations of voriconazole (0.7-1.4-2.8-5.6-11.2 $\mathrm{mg} / \mathrm{L})$. The influence of temperature on PPB was investigated by conducting the HT-ED at $25^{\circ} \mathrm{C}$ and at $37^{\circ} \mathrm{C}$. Variations in PPB of voriconazole because of frozen storage at $-20^{\circ} \mathrm{C}$ were investigated up to 12 months. The influence of 1-3-5 freeze-thaw cycles on PPB was also investigated and the $\mathrm{pH}$ during $\mathrm{ED}$, during frozen storage, and during freeze-thawing was measured with a $\mathrm{pH}$ meter, model Consort C830 (Consort BVBA, Turnhout, Belgium).

For every experiment, including time to equilibrium, HT-ED analyses were conducted at least in triplicate. Except when investigating the influence of temperature on $\mathrm{ED}$, all experiments were performed at $37^{\circ} \mathrm{C}$.

Voriconazole PPB determined in blank plasma spiked with voriconazole was compared with the PPB measured in plasma from critically ill patients treated with voriconazole.

\section{In Vitro-Binding Characteristics of Voriconazole}

Binding characteristics of voriconazole to albumin and AAG were investigated at $37^{\circ} \mathrm{C}$ in $\mathrm{PBS}$ solutions with $40 \mathrm{~g} / \mathrm{L}$ albumin 

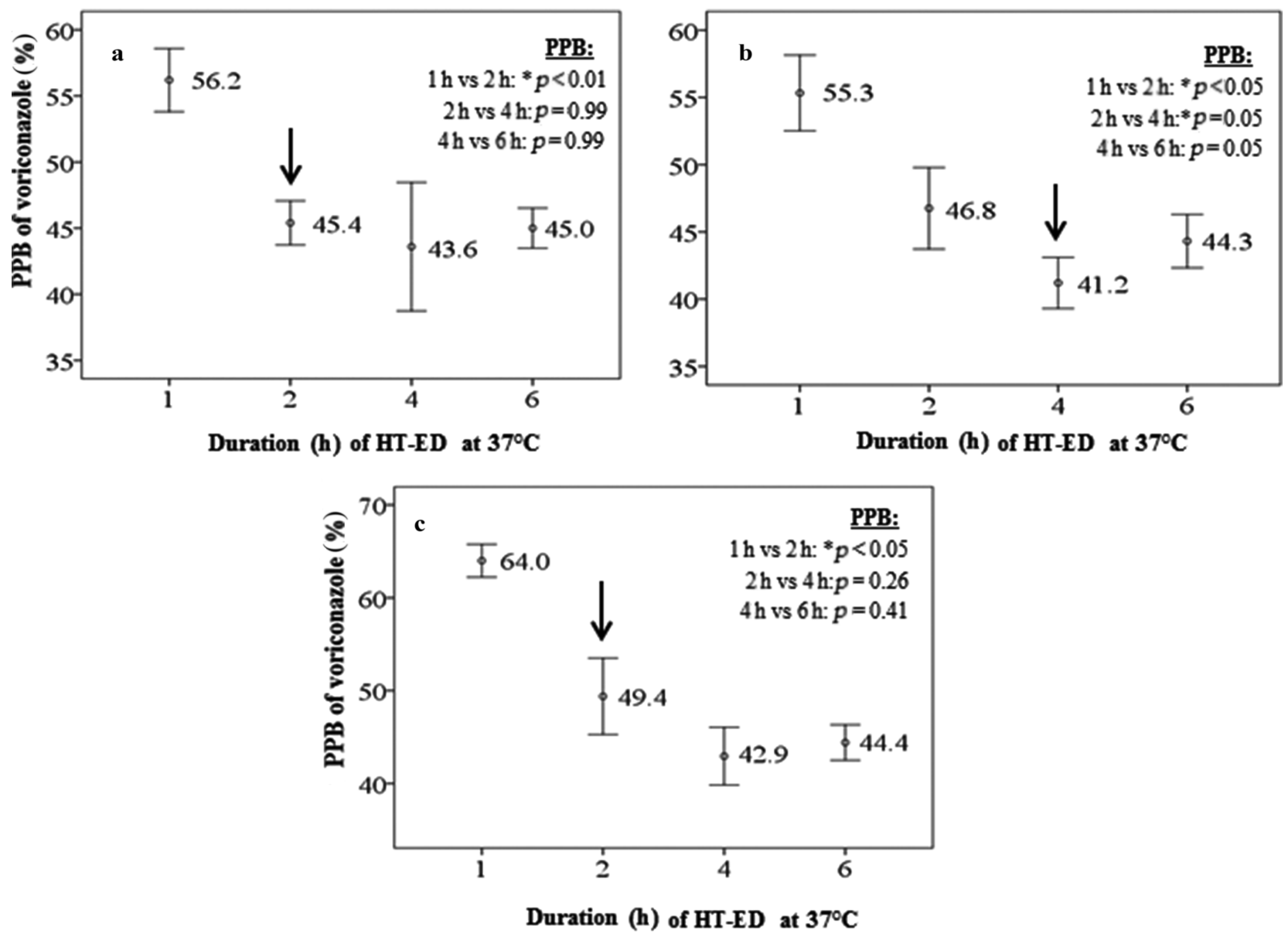

Figure 1. Time to equilibrium (h) for a total voriconazole concentration of $1.7 \mathrm{mg} / \mathrm{L}(\mathrm{a}), 3.5 \mathrm{mg} / \mathrm{L}$ (b), and $14 \mathrm{mg} / \mathrm{L}$ (c) in human blank plasma. ED was performed at $37^{\circ} \mathrm{C}$ during shaker incubation. Unbound and bound voriconazole concentrations were determined in triplicate for each time point with the HT-ED device followed by LC-MS/MS. ${ }^{30}$ Based on the graph combined with the $p$ values, equilibrium time (arrow) was set at $2 \mathrm{~h}$ (a and c), and $4 \mathrm{~h}(\mathrm{~b})$. *Significant difference.

(Albumin ${ }^{\circledR}$ 20\% $10 \mathrm{~mL}$; CAF), $1 \mathrm{~g} / \mathrm{L}$ AAG (Sigma-Aldrich BVBA) or both, spiked with a fixed voriconazole concentration of $3.5 \mathrm{mg} / \mathrm{L}$.

The potential differences in PPB of voriconazole associated with different commercial brands of human albumin were evaluated at $37^{\circ} \mathrm{C}$ by adding voriconazole $(3.5 \mathrm{mg} / \mathrm{L})$ to $40 \mathrm{~g} / \mathrm{L}$ albumin in PBS, using Albunorm ${ }^{\circledR}$ (Octapharma), Albumin ${ }^{\circledast} 20 \%$ (CAF), and Flexbumin ${ }^{\circledast} 200 \mathrm{~g} / \mathrm{L}$ (Baxter).

\section{Statistical Analysis}

Statistical analysis was performed using SPSS 20.0 for Windows (SPSS Inc. 2011, Chicago, Illinois). Depending on the distribution of data, median, and interquartile range (IQR) or mean and SD were calculated and the appropriate tests were used (unpaired $t$-test or Mann-Whitney U test; oneway ANOVA with post-hoc Tukey analysis or Kruskal Wallis test, repeated measures ANOVA test, Linear Mixed Models, or Friedman's test; Regression Analysis). $p<0.05$ was considered significant. The Bonferoni correction was used as multiplecomparison correction.

\section{RESULTS}

Equilibrium dialysis at $37^{\circ} \mathrm{C}$ during shaker incubation revealed an equilibration time of $2 \mathrm{~h}$ with 1.7 and $14 \mathrm{mg} / \mathrm{L}$ and $4 \mathrm{~h}$, with $3.5 \mathrm{mg} / \mathrm{L}$ total voriconazole concentrations (Fig. 1). On the basis of these results, an equilibrium time of $4 \mathrm{~h}$ was applied in all following experiments. Mass balance was confirmed, using an initial voriconazole concentration of $3.4 \mathrm{mg} / \mathrm{L}$ : the sum of voriconazole concentration in buffer and plasma compartment after $4 \mathrm{~h}$ of equilibrium at $37^{\circ} \mathrm{C}$ was $3.3 \pm 0.007 \mathrm{mg} / \mathrm{L}$, which is within the margins of the analytical variance of the LC-MS/MS method [95\% confidence interval (3.2 mg/L; $3.6 \mathrm{mg} / \mathrm{L})]$.

Plasma protein binding did not vary with different voriconazole concentrations at $37^{\circ} \mathrm{C}(p=0.65)$ (Table 1) and PPB was not influenced significantly when HT-ED was performed at $25^{\circ} \mathrm{C}$ versus $37^{\circ} \mathrm{C}(p=0.44)$, nor during $1-3-5$ freeze-thaw cycles, irrespective of total voriconazole concentration $(p=0.13)$ (Fig. 2a). No clinically significant changes in PPB were seen during the period of frozen storage ( $p=0.10$; data not shown). The sum of voriconazole concentration in PBS and in plasma remained stable overtime and did not differ from the concentrations of freshly prepared voriconazole in plasma solutions up to 1 year of frozen storage ( $p=0.96)$, indicating the stability of voriconazole in both fluids.

$\mathrm{pH}$ increased during ED at $37^{\circ} \mathrm{C}$, from 7.38 (freshly prepared plasma) to 7.68 (HT-ED during $6 \mathrm{~h}$ ), with a mean difference of $0.26 \pm 0.032 \mathrm{pH}$ units compared with $7.38(p<0.001)$. An increasing trend, with 0.0006 units per day $(p<0.001)$ was 
Table 1. Voriconazole (VRC) plasma protein binding (PPB) determined with HT-ED at $37^{\circ} \mathrm{C}$ during $4 \mathrm{~h}$ with human blank plasma spiked with different total VRC concentrations $(\mathrm{mg} / \mathrm{L})$

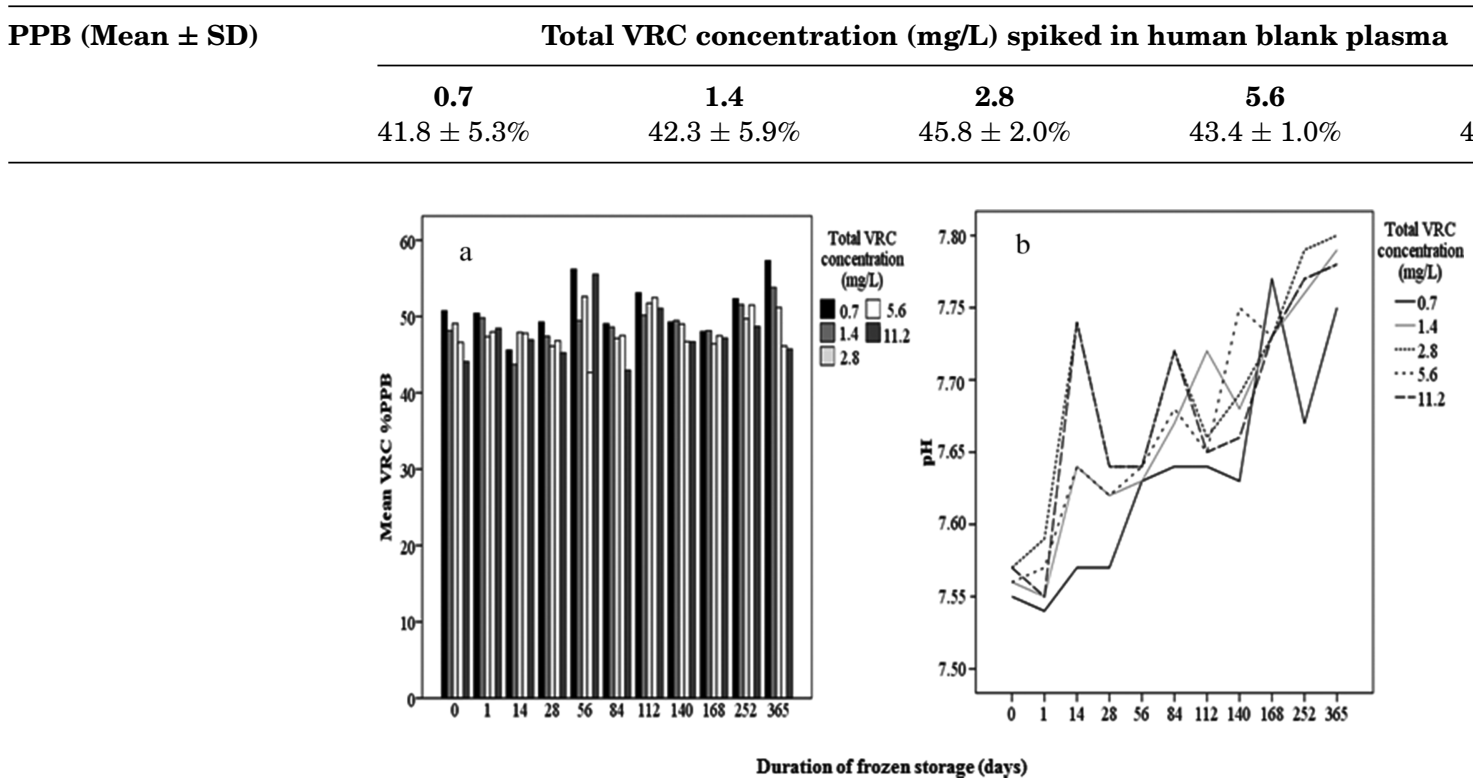

Figure 2. (a) Variation in plasma protein binding (PPB) of voriconazole during frozen storage up to 12 months. At each time point, PPB was determined in triplicate for five different total voriconazole concentrations in human blank plasma. (b) Variation in pH value of human blank plasma during frozen storage up to 12 months. Mean $\mathrm{pH}$ increased from 7.54 to 7.80 .

also seen in $\mathrm{pH}$ values during frozen storage, ranging from 7.54 in freshly spiked plasma to 7.80 after 12 months of storage (Fig. 2b).

In the in vitro experiment with albumin and AAG concentrations in PBS solution, voriconazole binds to albumin only for $25.5 \pm 5.1 \%$ and to AAG for $4.8 \pm 1.2 \%$. No clear difference was seen in PPB when using Albunorm ${ }^{\circledR} 200 \mathrm{~g} / \mathrm{L}$ (Octapharma), Albumine ${ }^{\circledR} 20 \% 10 \mathrm{~mL}(\mathrm{CAF})$, and Flexbumin ${ }^{\circledR}$ $200 \mathrm{~g} / \mathrm{L}$ (Baxter) $(33.4 \pm 9.3 \% ; 30.14 .1 \% ; 25.8 \pm 5.4 \%$, respectively; $p=0.23$ ).

Finally, the median (IQR) PPB of all in vitro experiments with blank plasma spiked with voriconazole $(N=235)$ was $47.6 \%(45.3 \%-50 \%)$, which did not differ significantly $(p=0.35)$ from the median PPB in 20 plasma samples from 13 ICU patients [49.6\% IQR 42.5\%-52.5\%)]. Median albumin and AAG concentrations in plasma of the ICU patients were $31.1 \mathrm{~g} / \mathrm{L}$ (IQR 28.4-33.2 g/L) and $1.8 \mathrm{~g} / \mathrm{L}(1.5-2.2 \mathrm{~g} / \mathrm{L})$, respectively. No exogenous albumin was administered within 1 month before sampling. The median total bilirubin plasma concentrations was 0.41 (IQR $0.28-1.69 \mathrm{mg} / \mathrm{dL}$ ). The median number of voriconazole treatment days was 6 (IQR 4-14) and the median total voriconazole plasma concentration was $2.4 \mathrm{mg} / \mathrm{L}$ (IQR 1.5-4.5)

\section{DISCUSSION}

We have tested an easily workable HT-ED assay for determination of the PPB of voriconazole. To our knowledge, this is the first time that voriconazole PPB characteristics are investigated thoroughly, with a robust method, excluding factors that significantly influence the in vitro performance of the HT-ED assay. We found that voriconazole PPB could be determined accurately and robustly using HT-ED without significant influence of several factors such as environmental temperature
( $p=0.44)$, freeze-thaw cycles $(p=0.13)$, and duration of frozen storage at $-20^{\circ} \mathrm{C}$ up to 12 months $(p=0.10) .^{31}$

Moreover, the Teflon material of the 96 -well plate prevents nonspecific adsorption of drug, as illustrated by the mass balance experiment. ${ }^{28}$ Volume shift, because of osmotic pressure, is minimal because equilibrium is already reached within 4 h. ${ }^{23,32}$ Because the stock solutions in methanol were first diluted in PBS buffer, the amount of solvent in the ED device was minimized to $0.02 \%-0.32 \%$, preventing influence from solvent addition on the protein-binding equilibrium. ${ }^{23,33}$

In all experiments, voriconazole PPB was independent of total voriconazole concentration, ranging from 0.7 to $14 \mathrm{mg} / \mathrm{L}$. Although the reference range of plasma voriconazole concentrations is set at 1 or $2-5.5 \mathrm{mg} / \mathrm{L}$, often subtherapeutic (below $1 \mathrm{mg} / \mathrm{L}$ ) and supratherapeutic (above $5.5 \mathrm{mg} / \mathrm{L}$ ) plasma concentrations are seen in patients treated with voriconazole. ${ }^{4,34}$ Because of the nonlinear pharmacokinetics, even plasma concentrations of $10-20 \mathrm{mg} / \mathrm{L}$ can be measured in some patients. This concentration independency can partly be explained because normal therapeutic voriconazole plasma concentrations ( 1 or $2-5.5 \mathrm{mg} / \mathrm{L}^{4,34}$ ) are many times smaller than the average plasma albumin concentration $( \pm 35-50 \mathrm{~g} / \mathrm{L}),{ }^{35}$ implying nonsaturated albumin binding.

The fluctuations in $\mathrm{pH}$ during ED and during frozen storage seen in this project are most likely irrelevant, although it is often suggested that they occur because of $\mathrm{CO}_{2}$ evaporation, ${ }^{36}$ possibly inducing conformational changes to plasma proteins, resulting in an altered binding profile. ${ }^{37,38}$ However, albumin conformational change only occurs at $\mathrm{pH}$ above $8 .{ }^{37} \mathrm{~A}$ change in degree of ionization of voriconazole because of $\mathrm{pH}$ changes is also not applicable, because voriconazole behaves as a weak base with a $\mathrm{pKa}$ value of $1.76 .^{39}$ The variations in PPB during frozen storage for different total voriconazole concentrations are most likely not relevant in clinical practice, because they are all fluctuating around $50 \%$. 
The median PPB, both in blank plasma spiked with voriconazole $[47.6 \%$ (IQR $45.3 \%-50 \%)]$ as in plasma from ICU patients treated with voriconazole $[49.6 \%(42.5 \%-52.5 \%)]$ differed from $58 \%$, as determined several years ago in the premarketing study. ${ }^{27}$ Despite the fact that these differences in PPB might not lead to major changes in pharmacokinetics insights of voriconazole, we believe that the difference should primarily be evaluated from a technical point of view and that our reported PPB is more accurate because of an improvement of the study design. ${ }^{27}$ First, and most importantly, the median in vitro PPB in our study was the result of 235 measurements, and was for the first time in literature, confirmed in plasma coming from 13 ICU patients treated with voriconazole. In the premarketing study, ${ }^{27}$ time to equilibrium was set at $2 \mathrm{~h}$, based on only one experiment with human plasma spiked with one concentration of voriconazole (i.e., $1 \mathrm{mg} / \mathrm{L}$ ) in triplicate, which differs from our experiment where time to equilibrium was determined to be $4 \mathrm{~h}$ at several different clinically relevant voriconazole concentrations. Second, the Dianorm Dialyzer was rotated at $15 \mathrm{rpm}$ during equilibration, compared with shaker incubation at $150 \mathrm{rpm}$ in our experiment, which could have influenced time to equilibrium. Differences in thickness and pore diameter of the membranes used in the Dianorm Dialyzer compared with our assay could have influenced the diffusion of unbound voriconazole molecules and therefore time to equilibrium. Roffey et al. ${ }^{27}$ used a volume of $1 \mathrm{~mL}$ plasma and buffer, compared with only $150 \mu \mathrm{L}$ at both sides of the membrane in the HT-ED device. Third, in the premarketing study, a $0.1 \mathrm{M}$ phosphate buffer was used, which can possibly cause more volume shift because of a higher osmolarity compared with the PBS solution with $0.012 \mathrm{M}$ phosphate used in the HT-ED device. Volume shift can alter the results, because in the calculations as mentioned in the Materials and Methods section of our manuscript, an equal volume in both compartments is assumed.

Fourth, as liquid scintillation counting, which is the analytical method used by Roffey et al., ${ }^{27}$ is more prone to measurement variations, it might have resulted in lower precision and accuracy compared with our LC-MS/MS method, ${ }^{30}$ possibly explaining in part the differences in protein binding of voriconazole between the two assays.

It is not completely clear whether these differences could have influenced the results; on the contrary, they cannot be neglected.

No information about mass balance is available for the Dianorm Dialyzer method.

To our knowledge, this is also the first study investigating which plasma components could be responsible for the total $\mathrm{PPB}$ of voriconazole. According to our results, albumin seems to be the main contributor to voriconazole $\mathrm{PPB}$, although in literature, basic drugs have shown to bind preferably to AAG. ${ }^{40}$ However, because only a PPB of approximately $30 \%$ was observed in vitro when combining clinically relevant concentrations of albumin and AAG, we believe that other components in human plasma are involved in voriconazole PPB, such as lipoproteins and $\alpha$-, $\beta$-, $\gamma$-globulins. ${ }^{23,40-43}$ The clinical relevance of these observations should be further explored.

As albumin was found to be the predominant protein determining voriconazole $\mathrm{PPB}$, we were interested in evaluating the potential differences in binding capacities of albumin from different commercial brands. The impact of the presence of different stabilizers and suppliers has been a matter of debate before. ${ }^{44}$ On the basis of our results, voriconazole PPB remained stable in vitro, irrespective of the commercial brand of albumin $(p=0.23)$. Furthermore, the method described in this manuscript can be used in future clinical studies investigating our hypothesis about the influence of hypoalbuminemia on voriconazole protein-binding characteristics, despite its moderate protein binding.

The disadvantages of HT-ED, being its time-consuming nature ( $\pm 2 \mathrm{~h}$ of preparation and $4 \mathrm{~h}$ of equilibration) and the costs of the device, do not outweigh the advantages such as the possibility of batch analysis, the easy assembly, use and cleaning, the compatibility with multichannel equipment, and most important, the possibility of automatization. ${ }^{28,29}$

\section{CONCLUSION}

Voriconazole protein binding is approximately 50\% in human plasma, according to an accurate, easy usable HT-ED method. As albumin is the main contributor to voriconazole PPB, this HT-ED-based method can be used in future studies to elucidate the influence of hypoalbuminemia on voriconazole pharmacokinetics and its relevance in clinical practice.

\section{ACKNOWLEDGMENTS}

The authors kindly thank Pfizer for the donation of voriconazole pure substance.

Kim Vanstraelen has received travel support from Gilead, MSD, and Pfizer, and received lecture honoraria from Pfizer. Joost Wauters has received research grants from MSD and Pfizer, and received travel support from MSD and Pfizer. Katrien Lagrou has received research grants, travel support, and lecture honoraria from Gilead, MSD, and Pfizer. Isabel Spriet has received research grants from $\mathrm{MSD}$ and Pfizer, received travel support from Gilead, MSD, and Pfizer, and received lecture honoraria from Gilead, MSD, and Pfizer.

\section{REFERENCES}

1. Walsh TJ, Anaissie EJ, Denning DW, Herbrecht R, Kontoyiannis DP, Marr KA, Morrison VA, Segal BH, Steinbach WJ, Stevens DA, van Burik JA, Wingard JR, Patterson TF. 2008. Treatment of aspergillosis: Clinical practice guidelines of the Infectious Diseases Society of America. Clin Infect Dis 46(3):327-360.

2. Trifilio S, Ortiz R, Pennick G, Verma A, Pi J, Stosor V, Zembower T, Mehta J. 2005. Voriconazole therapeutic drug monitoring in allogeneic hematopoietic stem cell transplant recipients. Bone Marrow Transplant 35(5):509-513.

3. Pascual A, Nieth V, Calandra T, Bille J, Bolay S, Decosterd LA, Buclin T, Majcherczyk PA, Sanglard D, Marchetti O. 2007. Variability of voriconazole plasma levels measured by new high-performance liquid chromatography and bioassay methods. Antimicrob Agents Chemother 51(1):137-143.

4. Pascual A, Calandra T, Bolay S, Buclin T, Bille J, Marchetti O. 2008. Voriconazole therapeutic drug monitoring in patients with invasive mycoses improves efficacy and safety outcomes. Clin Infect Dis 46(2):201211.

5. Okuda T, Okuda A, Watanabe N, Takao M, Takayanagi K. 2008. Retrospective serological tests for determining the optimal blood concentration of voriconazole for treating fungal infection. Yakugaku Zasshi 128(12):1811-1818.

6. Trifilio SM, Yarnold PR, Scheetz MH, Pi J, Pennick G, Mehta J. 2009. Serial plasma voriconazole concentrations after allogeneic 
hematopoietic stem cell transplantation. Antimicrob Agents Chemother 53(5):1793-1796.

7. Berge M, Guillemain R, Boussaud V, Pham MH, Chevalier P, Batisse A, Amrein C, Dannaoui E, Loriot MA, Lillo-Le Louet A, Billaud EM. 2009. Voriconazole pharmacokinetic variability in cystic fibrosis lung transplant patients. Transpl Infect Dis 11(3):211-219.

8. Miyakis S, van Hal SJ, Ray J, Marriott D. 2010. Voriconazole concentrations and outcome of invasive fungal infections. Clin Microbiol Infect 16(7):927-933.

9. Dolton MJ, Ray JE, Chen SC, Ng K, Pont LG, McLachlan AJ. 2012. Multicenter study of voriconazole pharmacokinetics and therapeutic drug monitoring. Antimicrob Agents Chemother 56(9):47934799.

10. Racil Z, Winterova J, Kouba M, Zak P, Malaskova L, Buresova L, Toskova M, Lengerova M, Kocmanova I, Weinbergerova B, Timilsina S, Rolencova M, Cetkovsky P, Mayer J. 2012. Monitoring trough voriconazole plasma concentrations in haematological patients: Real life multicentre experience. Mycoses 55(6):483-492.

11. Hoenigl M, Duettmann W, Raggam RB, Seeber K, Troppan K, Fruhwald S, Prueller F, Wagner J, Valentin T, Zollner-Schwetz I, Wolfler A, Krause R. 2013. Potential factors for inadequate voriconazole plasma concentrations in intensive care unit patients and patients with hematological malignancies. Antimicrob Agents Chemother 57(7):3262-3267.

12. Purkins L, Wood N, Ghahramani P, Greenhalgh K, Allen MJ, Kleinermans D. 2002. Pharmacokinetics and safety of voriconazole following intravenous- to oral-dose escalation regimens. Antimicrob Agents Chemother 46(8):2546-2553.

13. Ueda K, Nannya $Y$, Kumano $K$, Hangaishi A, Takahashi T, Imai $Y$, Kurokawa M. 2009. Monitoring trough concentration of voriconazole is important to ensure successful antifungal therapy and to avoid hepatic damage in patients with hematological disorders. Int $\mathrm{J}$ Hematol 89(5):592-599.

14. Scholz I, Oberwittler H, Riedel KD, Burhenne J, Weiss J, Haefeli WE, Mikus G. 2009. Pharmacokinetics, metabolism and bioavailability of the triazole antifungal agent voriconazole in relation to CYP2C19 genotype. Br J Clin Pharmacol 68(6):906-915.

15. Hyland R, Jones BC, Smith DA. 2003. Identification of the cytochrome $\mathrm{P} 450$ enzymes involved in the $\mathrm{N}$-oxidation of voriconazole. Drug Metab Dispos 31(5):540-547.

16. Weiler S, Zoller H, Graziadei I, Vogel W, Bellmann-Weiler R, Joannidis M, Bellmann R. 2007. Altered pharmacokinetics of voriconazole in a patient with liver cirrhosis. Antimicrob Agents Chemother 51(9):3459-3460.

17. Han K, Capitano B, Bies R, Potoski BA, Husain S, Gilbert S, Paterson DL, McCurry K, Venkataramanan R. 2010. Bioavailability and population pharmacokinetics of voriconazole in lung transplant recipients. Antimicrob Agents Chemother 54(10):4424-4431.

18. Hope WW. 2012. Population pharmacokinetics of voriconazole in adults. Antimicrob Agents Chemother 56(1):526-531.

19. Purkins L, Wood N, Kleinermans D, Greenhalgh K, Nichols D. 2003. Effect of food on the pharmacokinetics of multiple-dose oral voriconazole. Br J Clin Pharmacol 56(Suppl 1):17-23.

20. Mohammedi I, Piens MA, Padoin C, Robert D. 2005. Plasma levels of voriconazole administered via a nasogastric tube to critically ill patients. Eur J Clin Microbiol Infect Dis 24(5):358-360.

21. Ulldemolins M, Roberts JA, Rello J, Paterson DL, Lipman J. 2011. The effects of hypoalbuminaemia on optimizing antibacterial dosing in critically ill patients. Clin Pharmacokinet 50(2):99-110.

22. Wan H, Rehngren M. 2006. High-throughput screening of protein binding by equilibrium dialysis combined with liquid chromatography and mass spectrometry. J Chromatogr A 1102(1-2):125-134.

23. Howard ML, Hill JJ, Galluppi GR, McLean MA. 2010. Plasma protein binding in drug discovery and development. Comb Chem High Throughput Screen 13(2):170-187.
24. Sebille B, Zini R, Madjar CV, Thuaud N, Tillement JP. 1990. Separation procedures used to reveal and follow drug-protein binding. $\mathrm{J}$ Chromatogr 531:51-77.

25. Sebille B. 1990. Methods of drug protein binding determinations. Fundam Clin Pharmacol 4(Suppl 2):151s-161s.

26. Pacifici GM, Viani A. 1992. Methods of determining plasma and tissue binding of drugs. Pharmacokinetic consequences. Clin Pharmacokinet 23(6):449-468.

27. Roffey SJ, Cole S, Comby P, Gibson D, Jezequel SG, Nedderman AN, Smith DA, Walker DK, Wood N. 2003. The disposition of voriconazole in mouse, rat, rabbit, guinea pig, dog, and human. Drug Metab Dispos 31(6):731-741.

28. Banker MJ, Clark TH, Williams JA. 2003. Development and validation of a 96-well equilibrium dialysis apparatus for measuring plasma protein binding. J Pharm Sci 92(5):967-974.

29. Waters NJ, Jones R, Williams G, Sohal B. 2008. Validation of a rapid equilibrium dialysis approach for the measurement of plasma protein binding. J Pharm Sci 97(10):4586-4595.

30. Pauwels S, Vermeersch P, Van Eldere J, Desmet K. 2012. Fast and simple LC-MS/MS method for quantifying plasma voriconazole. Clin Chim Acta 413(7-8):740-743.

31. Kristensen CB, Gram LF. 1982. Equilibrium dialysis for determination of protein binding or imipramine-Evaluation of a method. Acta Pharmacol Toxicol (Copenh) 50(2):130-136.

32. Lagrange F, Penhourcq F, Matoga M, Bannwarth B. 2000. Binding of ketoprofen enantiomers in various human albumin preparations. $J$ Pharm Biomed Anal 23(5):793-802.

33. Ha CE, Petersen CE, Park DS, Harohalli K, Bhagavan NV. 2000. Investigations of the effects of ethanol on warfarin binding to human serum albumin. J Biomed Sci 7(2):114-121.

34. Troke PF, Hockey HP, Hope WW. 2011. Observational study of the clinical efficacy of voriconazole and its relationship to plasma concentrations in patients. Antimicrob Agents Chemother 55(10):4782-4788. 35. Vincent JL, Dubois MJ, Navickis RJ, Wilkes MM. 2003. Hypoalbuminemia in acute illness: Is there a rationale for intervention? A metaanalysis of cohort studies and controlled trials. Ann Surg 237(3):319 334.

36. Kochansky CJ, McMasters DR, Lu P, Koeplinger KA, Kerr HH, Shou M, Korzekwa KR. 2008. Impact of $\mathrm{pH}$ on plasma protein binding in equilibrium dialysis. Mol Pharm 5(3):438-448.

37. Otosu T, Nishimoto E, Yamashita S. 2010. Multiple conformational state of human serum albumin around single tryptophan residue at various $\mathrm{pH}$ revealed by time-resolved fluorescence spectroscopy. J Biochem 147(2):191-200.

38. Leonard WJ Jr, Vijai KK, Foster JF. 1963. A structural transformation in bovine and human plasma albumins in alkaline solution as revealed by rotatory dispersion studies. J Biol Chem 238:1984-1988. 39. Damle B, Varma MV, Wood N. 2011. Pharmacokinetics of voriconazole administered concomitantly with fluconazole and populationbased simulation for sequential use. Antimicrob Agents Chemother 55(11):5172-5177.

40. Ascenzi P, Fanali G, Fasano M, Pallottini V, Trezza V. Clinical relevance of drug binding to plasma proteins. J Mol Struct [In Press]. 41. Lindup WE, Orme MC. 1981. Clinical pharmacology: Plasma protein binding of drugs. Br Med J (Clin Res Ed) 282(6259):212-214. 42. Kurz H, Michels H, Stickel HH. 1977. Differences in the binding of drugs to plasma proteins from newborn and adult man. II. Eur J Clin Pharmacol 11(6):469-472.

43. Kurz H, Mauser-Ganshorn A, Stickel HH. 1977. Differences in the binding of drugs to plasma proteins from newborn and adult man. I. Eur J Clin Pharmacol 11(6):463-467.

44. De Bruyn T, Meijers B, Evenepoel P, Laub R, Willems L, Augustijns P, Annaert P. 2012. Stability of therapeutic albumin solutions used for molecular adsorbent recirculating system-based liver dialysis. Artif Organs 36(1):29-41. 